\title{
Gall Bladder Retrieval through Umbilical versus Epigastric Port in Conventional Four Port Laparoscopic Cholecystectomy.
}

1. FCPS

Senior Registrar Surgery

Jinnah Hospital, Lahore.

2. FCPS, MRCS, FMIS

Assistant Professor Surgery

Allama Iqbal Medical College Lahore.

3. FCPS, MRCS, FMBS

Assistant Professor Surgery

Allama Iqbal Medical College Lahore.

4. FCPS

Assistant Professor Surgery Allama Iqbal Medical College Lahore.

5. MBBS

Postgraduate Trainee Pediatric

Surgery

Sheikh Zayed Medical College \&

Hospital Rahim Yaar Khan.

Correspondence Address:

Dr. Sajid Malik

Department of Surgery

Allama Iqbal Medical College/

Jinnah Hospital Lahore, Pakistan.

drsajidmalik@yahoo.com

Article received on:

10/10/2020

Accepted for publication:

$12 / 02 / 2021$

\section{INTRODUCTION}

Incidence of gallstones in adults is almost 10-15\% but only $1-4 \%$ of these are symptomatic. ${ }^{1}$ Open cholecystectomy has become second line of surgical treatment after establishment of safety of laparoscopic cholecystectomy, later has become gold standard surgical treatment for both acute and chronic cholecystitis. ${ }^{2,3}$ Conventionally the procedure was carried out through four ports. However, now there is a trend of reducing the number and sizes of port sites. ${ }^{4}$

Traditional way of removed gall balder in laparoscopic surgery is through umbilical port. ${ }^{5}$ In this approach, surgeon has to change his position and telescope has to be changed in xiphoid port. Another approach to remove the gallbladder is through $10 \mathrm{~mm}$ xiphoid port without changing position of telescope and surgeon. ${ }^{6,7}$
Both approaches are compared for their pros and cons regarding time to retrieve gall bladder, post-operative pain at site of removal, difficulty in removal, and port site infection. Siddiqui NA et al when compared post-operative pain in xiphoid and umbilical port, it showed that there is less pain in retrieving specimen from umbilical post on visual analogue scale (VAS) as $5.9+1.1$ vs $4.1+1.5$ at 1 hour; $4.6+0.94$ vs $3.5+1.05$ at 6 hours; $3.9+0.85$ vs $2.4+0.79$ at 12 hours and $3.05+0.87$ vs 2.15 +0.87 at 24 hours with significant $p<0.001 .{ }^{8} \mathrm{He}$ concluded gall bladder removal through umbilical port causes less post-operative pain. However, another study by Azhar Bashir et al VAS at xiphoid port site was $3.54+1.034$ and at umbilical port site was $3.11+1.368$ ( $P$ value $>0.005$ ). These authors believe that both ports are equally effective in terms of postoperative pain. ${ }^{9}$ Although many surgeons have compared gallbladder retrieval 
through umbilical and xiphoid approach but still data lacks the establishment of superiority of one on other. Both above mentioned studies have shown different results in terms of postoperative pain which needs to be probed the situation further in order to establish hospital protocol and would ultimately a contribution to the national guidelines as standard procedure.

\section{MATERIAL \& METHODS}

This randomized control study was done in department of surgery of Allama Iqbal Medical College/ Jinnah Hospital Lahore from Aug 2017 to Feb 2018 and total of 70 cases were selected. Non probability/ consecutive sampling. A sample size of 70 patients, (35 in group I and 35 in group II) is calculated with $80 \%$ power of test, $5 \%$ level of significance and taking mean pain score of umbilical port as $2.15+0.87$ and xiphoid port as $3.05+0.87 .^{8}$

\section{Inclusion Criteria}

- Both male and female gender

- Proven echographic acute cholecystitis. (annexure attached) as per operational definition

- grade 1 acute cholecystitis (annexure for severity attached)

- ASA 1 and 2 patients( annexure attached)

- Age between 18years to 50years

- No history of laparotomy diagnosed on history and examination

\section{Exclusion Criteria}

- Pregnancy diagnosed on dip stick

- leukocytes more than 11000

- perforated cholecystitis diagnosed on examination and ultrasonography

- Peritonitis diagnosed on examination and ultrasonography

- Diagnosed cases of common bile duct dilatation (>8 $\mathrm{mm}$ in diameter on ultrasound), choledocholithiasis, pancreatitis and mass in gallbladder on ultrasound abdomen.

After proper prepping and draping, and preparing laparoscopic instruments, and a final sign out call; an infraumbilical $1.5 \mathrm{~cm}$ vertical incision is made on skin and deepened deep down until linea Alba is approached which is holded and retracted in upward direction and is incised. Two lips of linea Alba are then secured in an absorbable suture and is retracted to expose peritoneum. Peritoneum is lifted in an artery forceps and an incision is made on it for safe entry into abdomen using Hasson's port and is secured with stay sutures. Pneumoperitonium with $15 \mathrm{mmHg}$ pressure is created.

Diagnostic laparoscopy is a standard step before proceeding with xiphoid port. This port is chosen by internal visualization and external pressure technique, and a safe entry site through $10-12 \mathrm{~mm}$ skin incision is made to introduce a $10 \mathrm{~mm}$ port through it. Two more $5 \mathrm{~mm}$ trocars are placed at appropriate sites on lateral wall keeping in view good ergonomics for functional azimuth and manipulation angle.

Gall bladder is retracted in cephalad position towards ipsilateral shoulder and cholecystectomy is performed. Once dissection is complete, gall bladder is then placed in sub phrenic space while holding it in grasper through $5 \mathrm{~mm}$ ports. Camera is shifted to epigastric port and a retrieval bag is introduced through umbilical port for removal of gall bladder. Abdomen is washed if needed and a final look for hemostasis is given in a neutral bed position.

All ports are removed under direct vision with an aim to remove hasson's port in the end which is then closed with stay sutures taken in the start. Rest of the ports are closed with absorbable sutures, followed by skin adhesive tape or glue.

Port site herniation is a known complication after minimally invasive laparoscopic procedures. Although the incidence is low but should be considered for closure. Tonouchi et $\mathrm{al}^{10}$ recommended to close all port sites bigger than $10 \mathrm{~mm}$ as they found an incidence port site herniation as $0.65-2.8 \%$.

Cases fulfilling the inclusion criteria were selected from surgical out door department Jinnah hospital Lahore. Informed consent was taken, procedure was explained to patient and 
the patient was assured that his/her data was kept confidential. Ethical approval was obtained. All data was collected in pre designed proforma (attached). We randomly divided patients in two groups by using random number table as, group I in which gallbladder retrieved through umbilical port and patients in group II had their gallbladder retrieved through xiphoid port. All patients had standard post-operative care including standard analgesia, Nalbuphine $0.1 \mathrm{mg} / \mathrm{kg}$ I/V X 8 Hourly and Diclofenac Na 75mg I/M BD for 2 days. Postoperative pain was assessed by visual analogue scale at 1,6,12,24 and 48 hours.

Patient's data was entered and then analyzed using SPSS V. 20. Quantitative data like age and post-operative pain was described as mean and standard deviation while gender was presented as frequency and percentage. Both groups were compared through t test. Effect modifiers such as age, gender, BMI and educational status were addressed by stratification of patients in both groups. Independent sample T-test was applied for age and post-operative pain. $P$ value was considered significant if $<0.05$.

\section{RESULTS}

A total of 70 patients, (35 in group I and 35 in group II) fulfilling the inclusion/exclusion criteria were enrolled to compare mean post-operative pain in gall bladder retrieval from two different locations, either umbilical port or xiphoid port in conventional laparoscopic cholecystectomy with four ports for acute cholecystitis.

Age distribution of the patients was done, it shows that $20 \%(n=7)$ in Group-I and $34.29 \%(n=12)$ in Group-Il were between 18-30 years of age whereas $80 \%(n=28)$ in Group-I and $65.71 \%(n=23)$ in Group-II were between 31-50 years of age, mean + sd was calculated as $36.17+5.88$ years in Group-I and 33.86+6.01 years in Group-II. (Table-I)

Gender distribution shows that $37.14 \%(n=13)$ in Group-I and $40 \%(n=14)$ in Group-II were male whereas $62.86 \%(n=22)$ in Group-I and $60 \%(n=21)$ in Group-II were females. (Table-II)

Mean post-operative pain visual analogue scale (VAS) was calculated as $4.14+0.77 \mathrm{v} / \mathrm{s}$ $5.26+0.66$, p value 0.0001 at 1 hour in Group-I \& II, $3.40+0.50 \mathrm{v} / \mathrm{s} 4.09+0.82$, p value 0.0001 at 6 hour in Group-I \& II, 2.49+0.51 v/s 3.34+0.48, p value 0.0001 at 12 hour in Group-I \& II, 2.34+0.48 $\mathrm{v} / \mathrm{s} 2.97+0.51$, p value 0.0001 at 24 hour in Group-I \& II, 1.94+0.42 v/s 2.49+0.49, p value 0.0001 at 48 hour in Group-I \& II. (Table-III)

Effect modifiers such as age, gender, BMI and educational status wereaddressed by stratification of patients in both groups. Independent sample T-test was applied for age and post-operative pain. $P$ value was considered significant if $<0.05$. (Table-IV-VII).

\begin{tabular}{|c|c|c|c|c|}
\hline \multirow{2}{*}{ Age (in years) } & \multicolumn{2}{|c|}{ Group-I $(n=35)$} & \multicolumn{2}{|c|}{ Group-II $(n=35)$} \\
\hline & No. of Patients & $\%$ & No. of Patients & $\%$ \\
\hline $18-30$ & 7 & 20 & 12 & 34.20 \\
\hline $31-50$ & 28 & 80 & 23 & 65.71 \\
\hline Total & 35 & 100 & 35 & 100 \\
\hline Mean + SD & \multicolumn{2}{|c|}{$36.17+5.88$} & \multicolumn{2}{|c|}{$33.86+6.01$} \\
\hline
\end{tabular}

\begin{tabular}{|l|c|c|c|c|}
\hline \multirow{2}{*}{ Gender } & \multicolumn{2}{|c|}{ Group-I (n=35) } & \multicolumn{2}{c|}{ Group-II (n=35) } \\
\hline Male & No. of Patients & $\%$ & No. of Patients & 14 \\
\hline Female & 13 & 37.14 & 21 & 60 \\
\hline Total & 22 & 62.86 & 35 & 100 \\
\hline
\end{tabular}




\begin{tabular}{|l|c|c|c|c|c|}
\hline \multirow{2}{*}{$\begin{array}{c}\text { Post- operative } \\
\text { Pain (hours) }\end{array}$} & \multicolumn{2}{|c|}{ Group-I $(\mathbf{n = 3 5 )}$} & \multicolumn{2}{c|}{ Group-II $(\mathbf{n = 3 5})$} & \multirow{2}{*}{ P-Value } \\
\hline 1 & Mean & SD & Mean & SD & 0.0001 \\
\hline 6 & 4.14 & 0.77 & 5.26 & 0.66 & 0.0001 \\
\hline 12 & 3.40 & 0.50 & 4.09 & 0.82 & 0.0001 \\
\hline 24 & 2.49 & 0.51 & 3.34 & 0.48 & 0.0001 \\
\hline 48 & 2.34 & 0.48 & 2.97 & 0.51 & 0.0001 \\
\hline
\end{tabular}

Table-III. Comparison of mean post-operative pain in both groups after gall bladder retrieval after conventional laparoscopic cholecystectomy with four ports. $(n=70)$

\begin{tabular}{|c|c|c|c|c|c|}
\hline \multirow{2}{*}{$\begin{array}{c}\text { Post- operative } \\
\text { Pain }\end{array}$} & \multicolumn{2}{|c|}{ Group-I $(\mathbf{n = 3 5})$} & \multicolumn{2}{c|}{ Group-II $(\mathbf{n = 3 5})$} & P-Value \\
\hline & Mean & SD & Mean & SD & 0.0001 \\
\hline
\end{tabular}

Table-IV. Stratification for comparison of mean post-operative pain (at 48 hours) in both groups in regards to age. $(n=70)$.

\section{Age: $18-30$ years.}

\begin{tabular}{c|c|c|c|c|c|}
\multirow{2}{*}{$\begin{array}{c}\text { Post- operative } \\
\text { Pain }\end{array}$} & \multicolumn{2}{|c|}{ Group-I $(\mathbf{n = 3 5})$} & \multicolumn{2}{c|}{ Group-II $(\mathbf{n = 3 5})$} & \multirow{2}{*}{ P-Value } \\
\cline { 2 - 5 } & Mean & SD & Mean & SD & 0.0001 \\
\hline
\end{tabular}

Table-V. Stratification for comparison of mean post-operative pain in both groups in regards to gender $(n=70)$

Age: $31-50$ years

\begin{tabular}{c|c|c|c|c|c|}
\hline & \multicolumn{2}{|c|}{ Group-I $(\mathbf{n = 3 5})$} & \multicolumn{2}{c|}{ Group-II $(\mathbf{n = 3 5})$} & \multirow{2}{*}{ P-Value } \\
\hline \multirow{2}{*}{$\begin{array}{c}\text { Post- operative } \\
\text { pain }\end{array}$} & Mean & SD & Mean & SD & 0.0001 \\
\hline & 1.90 & 0.40 & 2.44 & 0.51 & 0.0001 \\
\hline
\end{tabular}

Table-VI. Stratification for comparison of mean post-operative pain in both groups with regards to BMI. $(n=70)$.

\section{Male \& Female}

\begin{tabular}{c|c|c|c|c|c|}
\hline & \multicolumn{2}{|c|}{ Group-I $(\mathbf{n}=\mathbf{3 5})$} & \multicolumn{2}{c|}{ Group-II $(\mathbf{n = 3 5})$} & \multirow{2}{*}{ P-Value } \\
\hline \multirow{2}{*}{$\begin{array}{c}\text { Post- operative } \\
\text { Pain }\end{array}$} & Mean & SD & Mean & SD & \\
\cline { 2 - 6 } & 1.95 & 0.43 & 2.46 & 0.55 & 0.0001 \\
\cline { 2 - 6 } & 1.96 & 0.44 & 2.48 & 0.56 & 0.0001 \\
\hline
\end{tabular}

\section{Up to $30>30$}

\begin{tabular}{|c|c|c|c|c|c|c|}
\hline & & \multicolumn{2}{|c|}{ Group-I $(\mathbf{n = 3 5 )}$} & \multicolumn{2}{c|}{ Group-II (n=35) } & \multirow{2}{*}{ P-Value } \\
\cline { 2 - 7 } & & Mean & SD & Mean & SD & \\
\hline \multirow{3}{*}{$\begin{array}{c}\text { Post- operative } \\
\text { Pain }\end{array}$} & Illiterate & 1.91 & 0.43 & 2.47 & 0.55 & 0.0001 \\
\cline { 2 - 7 } & Primary & 1.93 & 0.40 & 2.46 & 0.58 & 0.0001 \\
\cline { 2 - 7 } & Middle & 1.93 & 0.45 & 2.46 & 0.55 & 0.0001 \\
\cline { 2 - 7 } & Matric \& above & 1.90 & 0.43 & 2.46 & 0.58 & 0.0001 \\
\hline
\end{tabular}

Table-VII. Stratification for comparison of mean post-operative pain in both groups regards to educational status $(n=70)$.

\section{DISCUSSION}

laparoscopic cholecystectomy is now the gold standard treatment for the symptomatic cholilithiasis all over the world. In conventional laparoscopic cholecystectomy, traditional way of gall bladder removal is through umbilical 
port. In this approach surgeon has to change his position and telescope has to be changed in xiphoid port. Another approach to remove the gallbladder is through $10 \mathrm{~mm}$ xiphoid port without changing position of telescope and surgeon. Both approaches are compared for their pros and cons regarding time to retrieve gall bladder, post-operative pain at site of removal, difficulty in removal and infection.

Although many surgeons have compared gallbladder retrieval through umbilical and xiphoid approach but still data lacks the establishment of superiority of one on other. Both above mentioned studies have shown different results in terms of postoperative pain which makes us to probe the situation further.

In this study, out of 70 cases (35 in each group), mean age was $36.17+5.88$ years in Group-I and $33.86+6.01$ years in Group-II, 37.14\% $(n=13)$ in Group-I and $40 \%(n=14)$ in Group-II were male whereas $62.86 \%(n=22)$ in Group-I and $60 \%(n=21)$ in Group-II were females, mean postoperative pain visual analogue scale (VAS) was calculated as $4.14+0.77 \mathrm{v} / \mathrm{s} 5.26+0.66$, at 1 hour in Group-I \& II, 3.40+0.50 v/s 4.09+0.82, at 6 hour in Group-I \& II, 2.49+0.51 v/s 3.34+0.48, at 12 hour in Group-I \& II, 2.34+0.48 v/s 2.97+0.51, at 24 hour in Group-I \& II, 1.94+0.42 v/s 2.49+0.49, at 48 hour in Group-I \& II.

We compared our results with Siddiqui NA who compared post-operative pain in xiphoid and umbilical port it showed mean post-operative pain higher in earlier than later on visual analogue scale (VAS) as $5.9+1.1$ vs $4.1+1.5$ at $1^{\text {st }}$ hour, $4.6+0.94$ vs $3.5+1.05$ at 6 hours, $3.9+0.85$ vs $2.4+0.79$ at 12 hours and $3.05+0.87$ vs 2.15 +0.87 at 24 hours with significant $p<0.001 .{ }^{8} \mathrm{He}$ concluded gall bladder removal through umbilical port causes less post-operative pain. Our results correspond to these findings.

In another study of Azhar Bashir VAS at xiphoid port site was $3.54+1.034$ and at umbilical port site was $3.11+1.368$ ( $P$ value 0.089 ). According to authors, both ports are equally effective in terms of post-operative pain ${ }^{9}$, these findings do not match with our results.

Our results are further supported by Jugendra Pal Singh Shakya and others ${ }^{15}$ who reported that the rate of pain and infection in gall bladder retrieval through epigastric port was less when compared with gall bladder retrieval from umbilical port. They reported that the post-operative pain at 24 hours, in terms of VAS (0-10) was significantly higher $(p=.000048) 3.67 \pm 1.42$ in Group-A while $2.47 \pm 1.17$ in Group-B. They concluded that gall bladder retrieval through umbilical port is a better way in terms of post-operative pain and port site infection in conventional four port laparoscopic cholecystectomy as compared to its counterpart of epigastric port extraction. Our study also suggest that the gall bladder extraction via umbilical port is a better technique as compared to using epigastric port for this job. However, we did not compare infection in both techniques which may be done in coming trials.

The result of our study justifies the hypothesis that "there is difference in mean pain score with gallbladder retrieval through umbilical versus xiphoid ports in four ports laparoscopic cholecystectomy in terms of post-operative pain" which may be validated through some other multicenter trials.

\section{CONCLUSION}

We concluded that mean post-operative pain had significantly reduced when gall bladder was retrieved from umbilical port instead of xiphoid port in conventional laparoscopic cholecystectomy for acute cholecystitis was done with four ports.

Copyright (C) 12 Feb, 2021.

\section{REFERENCES}

1. Gurusamy K, Samraj K, Gluud C. Meta-analysis of randomized controlled trials on the safety and effectiveness of early versus delayed laparoscopic cholecystectomy for acute cholecystitis. $\mathrm{Br} \mathrm{J}$ Surg. 2010;97:141-50

2. Abbas T, Saleha AK, Lateef M, Burhan-ul-Haq, Faisal R, Choudhary ZA. Procedural time and complications in delivery of gall bladder in laparoscopic cholecystectomy umbilical port versus subxiphoid port. J Allama lqbal Medical Col 2012; 9(4):54-7. 
3. Waqar SH, Shah SF, Khan IA, Ch TS, Abdullah TM, Malik ZI, Zahid MA. Two-port Laparoscopic cholecystectomy-A new technique. J Ayub Medical Coll 2008; 4(20):167-8.

4. Luna RA, Nogueira DB, Varela PS, NetoEd OR, Norton MJR, Luciana do Carrno BR. A prospective, randomized comparison of pain, inflammatory response and short-term outcomes between single port and laparoscopic cholecystectomy. Surg Endosccop 2013; 27(4):1254-9.

5. Chalkoo M, Ahangar S, Durrani AM, Chalkoo S, Shah MJ, Bashir MI. Mini-lap cholecystectomy: Modifications and innovations in technique. Inter J Surg 2010; 8(2):112-7.

6. Sun S, Yang K, Gao M, He X, Tian J, Ma B. Three-port versus four-port laparoscopic cholecystectomy: Meta-analysis of randomized clinical trials. World $\mathrm{J}$ Surg 2009; 33(9):1904-8.

7. Memon JM, Memon MR, Arija D, Bozdar AG, Talpur MM. Retrieval of gall bladder through epigastric port as compared to umbilical port after laparoscopic cholecystectomy. Pak J Pharm Sci 2014; 27(6 Spec No.):2165-8.

8. Siddiqui NA, Azami R, Murtaza G, Nasim S. Postoperative port-site pain after gall bladder retrieval from epigastric versus umbilical port in laparoscopic cholecystectomy: A randomized controlled trial. Int J Surg 2012; 10 (4):213-6.

9. Basher A, QURESHI AU, Afzal S. Comparison of Gall Bladder retrieval through umbilical port versus subxiphoid port in laparoscopic cholecystectomy. PJMHS; 2015:9(2):769-771.
10. Tonouchi $\mathrm{H}$, Ohmori $\mathrm{Y}$, Kobayashi M, Kusunoki M. Trocar site hernia. Arch Surg. 2004 Nov. 139(11):124856

11. Mutter D, Callari C, Diana M, Dallemagne B, Leroy $J$ and Marescaux J, "Single port laparoscopic cholecystectomy: which technique, which surgeon, for which patient? A study of the implementation in a teaching hospital," Journal of Hepato- BiliaryPancreatic Sciences 2011; 18: (3):453-57.

12. Yeo D, Mackay S and Martin D. "Single-incision laparoscopic cholecystectomy with routine intraoperative cholangiography and common bile duct exploration via the umbilical port," Surgical Endoscopy, 2012; 26:(4):1122-7.

13. Dominguez G, Durand L, De Rosa J, Danguise E, Arozamena $\mathrm{C}$ and Ferraina PA. "Retraction and triangulation with neodymium magnetic forceps for single-port laparoscopic cholecystectomy," Surgical Endoscopy 2009:23(7):1660-6.

14. Fransen S, Stassen $L$ and Bouvy N. "Single incision laparoscopic cholecystectomy: a review on the complications," Journal of Minimal Access Surgery, 2012; 8:(1):1-5.

15. Shakya JPS, Agrawal N, Kumar A, Singh A, Gogia B, Yadav C. A comparative study of the incidence of pain and infection in gall bladder extraction via umbilical and epigastric port. Int Surg J. 2017 Feb; 4(2):747-50.

\begin{tabular}{|c|l|l|l|}
\hline \multicolumn{3}{|c|}{ AUTHORSHIP } & AND CONTRIBUTION DECLARATION \\
\hline Sr. \# & Author(s) Full Name & \multicolumn{1}{|c|}{ Contribution to the paper } & Author(s) Signature \\
\hline 1 & Gul e Lala & $\begin{array}{l}\text { Provision of study Material, Data } \\
\text { assembly, Manuscript writing. } \\
\text { Admin support, Data analysis, } \\
\text { Manuscript writing. } \\
\text { Data collection, Concept and } \\
\text { study design. } \\
\text { Data collection, Concept and } \\
\text { study design. } \\
\text { Data collection, Concept and } \\
\text { study design. }\end{array}$ \\
\hline 5 & Sajid Malik & Mian Umar Javed & \\
\hline
\end{tabular}

